\title{
TROMBOFILIAS ADQUIRIDAS
}

\author{
ACQUIREDTHROMBOPHILIAS
}

Andrea A. Garcia ${ }^{1} \&$ Rendrik F. Franco ${ }^{2}$

\begin{abstract}
'Médica Assistente da Divisão de Hematologia do Hospital das Clínicas da FMRP-USP; Pós-Graduanda (Hematologia) do Departamento de Clínica Médica da FMRP-USP. ${ }^{2}$ Professor Livre-Docente de Hematologia e Hemoterapia. Coordenador do Serviço de Investigação em Hemofilia e Trombofilia, Fundação Hemocentro de Ribeirão Preto. Coordenador do Laboratório de Hemostasia. Hospital das Clínicas da Faculdade de Medicina de Ribeirão Preto, Universidade de São Paulo.

CorRespondência: FUNDHERP, Rua Tenente Catão Roxo, 2501 - 14051-140, Ribeirão Preto, SP. E-mail: rendri@hotmail.com
\end{abstract}

GARCIA AA \& FRANCO RF. Trombofilias adquiridas. Medicina, Ribeirão Preto, 34: 258-268, jul./dez. 2001.

RESUMO: Na presente revisão, discutimos a contribuição de fatores de risco adquiridos para a ocorrência de tromboembolismo venoso.

UNITERMOS: Trombose. Fatores de Risco.

\section{INTRODUÇÃO}

$\mathrm{O}$ termo trombofilia refere-se à predisposição aumentada para a ocorrência de fenômenos tromboembólicos. Vários fatores de risco, genéticos ou adquiridos, estão envolvidos nos mecanismos fisiopatológicos, que resultam em trombose, tanto arterial como venosa ${ }^{(1,2,3)}$.

A Tabela I mostra os fatores de risco adquiridos, mais freqüentemente relacionados a fenômenos trombóticos venosos ${ }^{(4,5)}$. Neste capítulo, discutiremos as principais situações adquiridas, que constituem fatores de risco para o tromboembolismo venoso (TEV). Serão analisados os possíveis mecanismos fisiopatológicos que levam à formação de trombos, os recursos clínicos e laboratoriais disponíveis para diagnóstico das causas adquiridas de trombose e as recomendações terapêuticas vigentes nas seguintes condições clínicas: síndrome antifosfolípide, hemoglobinúria paroxística noturna, doenças mieloproliferativas, neoplasias, gestação e puerpério, síndrome nefrótica e hiperviscosidade.
Tabela I - Principais causas de trombofilia adquirida.

Fator de risco adquirido

- Síndrome do anticorpo antifosfolipídeo

- Hemoglobinúria paroxística noturna

- Doenças mieloproliferativas

- Neoplasias

- Gravidez e puerpério

- Síndrome nefrótica

- Hiperviscosidade

- Uso de anticoncepcional oral

- Medicamentos

- Trauma e operações

- Imobilização prolongada 


\section{SÍNDROME DO ANTICORPO ANTIFOSFO- LIPÍDEO}

A Síndrome do Anticorpo Antifosfolipídeo (SAF) caracteriza-se pela ocorrência de trombose arterial ou venosa, abortos recorrentes e trombocitopenia, associados à evidência laboratorial de anticorpos antifosfolipídeos (AAF). Os AAF incluem uma família de imunoglobulinas (IgG, IgM, IgA, ou mistas) auto-imunes, que reconhecem e se ligam a complexos de proteínas plasmáticas, associadas a fosfolipídeos de membrana, em testes laboratoriais in vitro. As duas principais proteínas plasmáticas que funcionam como alvos antigênicos nos complexos reconhecidos pelos AAF são a $\beta 2$-glicoproteína I ( $\beta 2 \mathrm{GPI}$ ) e a protrombina (fator II da coagulação). Outras proteínas que podem se ligar a fosfolípideos e formar o complexo alvo dos AAF incluem: apolipoproteína $\mathrm{H}$, proteína $\mathrm{C}$, proteína $\mathrm{S}$, anexina $\mathrm{V}$, fator $\mathrm{X}$, cininogênio de alto peso molecular, fator XI e o componente protéico do heparan-sulfato ${ }^{(6,7)}$. A diversidade desses potenciais complexos proteína/fosfolípideos, provavelmente, responde por uma das mais importantes características da SAF: sua heterogeneidade de manifestações clínicas e laboratoriais.

O espectro de manifestações trombóticas da SAF é amplo. Todas as idades são acometidas. Aproximadamente $70 \%$ dos eventos ocorrem em território venoso e $30 \%$ acometem território arterial. Podem ocorrer oclusões de artérias viscerais e periféricas, sendo os acidentes vasculares cerebrais uma complicação frequiente. Em território venoso, a trombose venosa profunda é a manifestação mais comum. $\mathrm{Cu}-$ riosamente, em casos de recorrência, há notável repetição do acometimento no mesmo território (isto é, trombose venosa recorre após manifestação de trombose venosa, e trombose arterial recorre após trombose arterial).

As complicações obstétricas, associadas à SAF, incluem abortos recorrentes, ocorrência precoce de pré-eclâmpsia, coréia da gestação, e retardo de crescimento fetal intra-uterino ${ }^{(8,9)}$. Abortos recorrentes ocorrem freqüentemente, mesmo em mulheres que não têm história prévia de trombose, e fazem parte dos critérios diagnósticos para SAF. Os critérios clínicos obstétricos para o diagnóstico de SAF estão descritos na Tabela II.

A trombocitopenia é encontrada em 20 a $45 \%$ dos pacientes com SAF, e é (supostamente) mediada por mecanismos imunológicos. Fazem ainda parte do quadro clínico de SAF o livedo reticular e alterações em válvulas cardíacas ${ }^{(6,10)}$. Finalmente, existe uma forma de SAF, denominada "catastrófica", com doença oclusiva vascular súbita, grave e fatal. É caracterizada por insuficiência renal, retinopatia, acidente vascular cerebral isquêmico, osteonecrose, necrose de pele, infarto agudo do miocárdio, coagulação intravascular disseminada e citopenias imunes ${ }^{(5)}$.

A análise laboratorial inicial de quadros de SAF baseia-se no prolongamento de um teste de coagulação, dependente de fosfolipídeos, o qual não apresenta correção após mistura com plasma normal. A correção pode ocorrer com excesso de fosfolipídeos. Há, deste modo, a evidência da presença de um inibidor, denominado anticoagulante lúpico (AL, denominação usada porque o anticorpo foi detectado, pela primeira vez, em pacientes com Lúpus Eritematoso Sistêmico, em 1948).

Os principais métodos laboratoriais utilizados para detecção de anticorpos do tipo anticoagulante lúpico encontram-se listados na Tabela III. Descrição dos detalhes metodológicos, envolvidos na execução desses testes, encontra-se fora do escopo deste texto, de tal sorte que as características dos testes e o impacto da presença de anticorpos do tipo anticoagulante lúpico, sobre os mesmos são apresentados de forma resumida. Recomenda-se a disponibilidade de, pelo menos, dois dos testes listados em laboratórios de hemostasia, envolvidos na investigação de distúrbios trombóticos.

Tabela II - Critérios clínicos obstétricos para SAF.

1- Uma ou mais mortes inexplicáveis, de um feto morfologicamente normal, observado por ultrasom ou por visão direta do feto, com 10 semanas ou mais de gestação

2- Um ou mais nascimentos prematuros, de neonato morfologicamente normal, antes ou na $34^{a}$ semana, devido a pré-eclâmpsia grave ou eclâmpsia, ou grave insuficiência placentária

3- Três ou mais abortos espontâneos consecutivos, inexplicáveis, antes da $10^{\mathrm{a}}$ semana de gestação, sem anormalidades hormonais ou anatômicas maternas ou causas cromossômicas materna ou paterna. 
Tabela III: Métodos laboratoriais, utilizados para detecção de anticoagulante lúpico.

\begin{tabular}{|c|c|c|}
\hline Teste & Descrição resumida do método & $\begin{array}{c}\text { Efeito do AAF no resulta- } \\
\text { do do teste }\end{array}$ \\
\hline TTPA & Plasma + Ativador (contato) $+\mathrm{FL}+\mathrm{Ca}^{++}$ & $\uparrow$ \\
\hline TCK & Plasma + Kaolin $+\mathrm{Ca}^{++}$ & $\uparrow \uparrow \uparrow$ \\
\hline TTPA (FL diluído) & Plasma +Sílica + FL diluído $+\mathrm{Ca}^{++}$ & $\uparrow \uparrow$ \\
\hline PNP & Plasma + Ativador $+\uparrow$ concentr. $\mathrm{FL}+\mathrm{Ca}^{++}$ & Normaliza \\
\hline dRVVT & Plasma + RVV + FL diluído + $\mathrm{Ca}^{++}$ & $\uparrow \uparrow$ \\
\hline TIT & Plasma + tromboplastina diluída $+\mathrm{Ca}^{++}$ & $\uparrow \uparrow$ \\
\hline \multicolumn{3}{|c|}{$\begin{array}{l}\text { TTPA, tempo de tromboplastina parcial ativada; TCK, tempo de coagulação com o kaolim; PNP, procedimento de neutralização } \\
\text { com plaquetas; dRVVT, diluted Russell viper venom time (tempo do veneno da víbora de Russell diluído); TIT, teste de inibição da } \\
\text { tromboplastina tecidual. }\end{array}$} \\
\hline
\end{tabular}

Outro método utilizado no diagnóstico laboratorial da SAF é a pesquisa de anticorpo anticardiolipina (AAC IgG e IgM), feita atualmente por método de ELISA, sendo a cardiolipina uma fonte de fosfolipídeo. A $\beta 2$ GPI ligada a um fosfolipídeo aniônico, como a cardiolipina, é que torna possível a detecção desse anticorpo.

Não obstante haja notável heterogeneidade de manifestações clínicas e laboratoriais, associadas à SAF, os critérios para diagnóstico da síndrome devem ser bem estabelecidos para efeito de clareza, e encontram-se apresentados na Tabela IV. Pacientes com SAF devem ter, pelo menos, um critério clínico e um critério laboratorial, sendo que os testes para AAF devem ser positivos pelo menos em duas ocasiões, separadas por intervalo de 6 semanas ${ }^{(11)}$.

A SAF pode ser considerada primária, secundária ou associada a outras situações clínicas (Tabela V). Quando não há qualquer evidência de uma doença de base, dizemos tratar-se de SAF primária. A pre- sença de uma doença auto-imune subjacente, geralmente LES, faz o diagnóstico de SAF secundária (Tabela V). Em casos de SAF primária, secundária a doenças auto-imunes e associada ao uso de medicações, os AAF são auto-imunes, ao passo que, na SAF associada a infecções e neoplasias, os AAF são heteroimunes.

A confirmação laboratorial da SAF pode representar tarefa difícil em muitos casos. Os exames utilizados para a pesquisa dos AAF nem sempre são conclusivos. Quando houver forte suspeita clínica de SAF e os testes acima forem negativos, além de repeti-los, pode-se realizar a pesquisa do anticorpos anticardiolipina $\operatorname{IgA}$ e anti- $\beta 2 \mathrm{GPI}^{(6,12)}$.

Vários estudos indicam que o AL é menos sensível, porém, mais específico que a AAC para o diagnóstico de $\mathrm{SAF}^{(6)}$.

$\mathrm{O}$ aparente paradoxo entre efeito anticoagulante (in vitro) e estado protrombótico (in vivo) dos AAF ainda não é bem compreendido, mas sabe-se que pacientes com SAF exibem evidência de persistente ativação da coagulação, demonstrada por níveis plasmáticos aumentados de marcadores da geração de trombina, como fragmento $1+2$ da protrombina e fibrinopeptídeo A. A Tabela VI mostra os possíveis mecanismos envolvidos na trombogênese da SAF ${ }^{(6)}$. 
Tabela V - Quadros associados ao Anticorpo Antifosfolipídeo.

\section{SAF primária}

- Doença tromboembólica arterial e/ou venosa, abortos recorrentes, trombocitopenia, sem doença de base identificada

\section{SAF Secundária}

- Associada a doenças reumáticas ou do tecido conectivo

- Lúpus eritematoso sistêmico, artrite reumatóide, esclerose sistêmica, arterite temporal, síndrome de Sjögren, artropatia psoriática, doença de Behçet

\section{Outras associações}

- Infecção viral (HIV, hepatite C, varicela), bacteriana (sífilis), parasitária (malária)

- Doenças linfoproliferativas (linfomas, paraproteinemias)

- Medicamentos (fenitoína, quinidina, hidralazina, procainamida)

- Miscelânea (púrpura trombocitopênica imune, anemia hemolítica auto-imune, anemia falciforme, síndrome de Guillain-Barre, livedo reticular, uso de droga endovenosa)

Anticorpo Antifosfolipídeo, sem manifestação clínica ou doença de base

Tabela VI - Mecanismos fisiopatológicos dos eventos trombóticos na SAF.

\section{Mecanismos de trombogênese}

1. Interferência dos anticorpos antifosfolipídeos (AAF) sobre as propriedades anticoagulantes da $\beta 2 \mathrm{GP}$ ।

2. Inibição pelos AAF da função anticoagulante da antitrombina e da proteína $\mathrm{C}$ ativada

3. Redução da fibrinólise

4. Ativação da via da coagulação dependente do fator tecidual

5. Inibição pelos AAF da secreção de prostaciclinas pelas células endoteliais

6. Liberação pelos AAF de fator de von Willebrand das células endoteliais

7. Ativação plaquetária

Por se tratar de condição clínica de extrema relevância e ligada a significativa morbidade, aspectos envolvendo profilaxia e tratamento de episódios trombóticos na SAF são de grande importância ${ }^{(13 / 16)}$. Inicialmente, deve ser mencionado que não há dados suficientes, disponíveis, que definam o risco de tromboembolismo venoso em indivíduos assintomáticos, que apresentam um teste positivo para anticoagulante lúpico ou anti-cardiolipina. Profilaxia com heparina (geralmente por 2 a 4 semanas) em situações de alto risco para trombose é, usualmente, recomendada nesse contexto. Nessa situação, atenção especial deve ser dada a pacientes com história prévia de TEV que não estão em uso de anticoagulante, nos quais profilaxia vigorosa e acompanhamento próximo devem ser estabelecidos.

No que tange ao tratamento do episódio agudo de TEV na SAF, o mesmo não difere de outras situações, baseando-se na administração de doses terapêuticas de heparina (não fracionada ou de baixo peso molecular), por pelo menos cinco dias, e transição para anticoagulação oral, preferencialmente com warfarin. Não há, na literatura, dados que permitam definir a duração ideal do tratamento com anticoagulante oral em pacientes com teste positivo para AAF. Em função da alta taxa de recorrência, parece razoável recomendar-se tratamento continuado por, pelo menos, um ano. Após interrupção do tratamento, recomendase repetição dos testes laboratoriais diagnósticos de SAF. Em casos de recorrência do TEV, de diagnóstico de trombofilia hereditária associada, e de combinação de episódio trombótico venoso e arterial, recomenda-se anticoagulação perene. Em pacientes com recorrência de fenômenos trombóticos arteriais e venosos, a administração perene da combinação de anticoagulante oral e aspirina é indicada. O uso combinado de aspirina e anticoagulante pode resultar em maior risco hemorrágico. A Tabela VII compila as recomendações gerais de tratamento do TEV na SAF.

$\mathrm{Na}$ maior parte dos casos de SAF, em que se faz necessário o uso de anticoagulação oral, o RNI (Razão Normatizada Internacional) pode ser mantido entre 2 e 3; garantindo baixa recorrência de trombose durante o tratamento e menor morbimortalidade decorrente de manifestações hemorrágicas ${ }^{(6)}$. Há dados derivados de estudos retrospectivos, apontando para necessidade de níveis mais intensos de anticoagulação para prevenção de trombose durante o tratamento dos pacientes com SAF ${ }^{(17)}$. Assim, o assunto permanece controverso.

A ocorrência de acidente vascular cerebral isquêmico, em paciente com SAF, é indicação de anticoagulação por longo período, devido ao alto índice de recorrência de trombose, à possibilidade de seqüelas neurológicas e morte. 


\begin{tabular}{|c|c|}
\hline \multicolumn{2}{|c|}{ Tabela VII: Tratamento do TEV na SAF. } \\
\hline Situação Clínica & Conduta \\
\hline $1^{\circ}$ episódio de TEV & $\begin{array}{l}\text { Heparinização plena (pelo menos } 5 \text { dias), seguida de ACO (RNI 2-3) por } \\
12 \text { meses }\end{array}$ \\
\hline $2^{\circ}$ episódio de TEV & Heparinização plena seguida de ACO perene \\
\hline $\begin{array}{l}\text { TH associada ou } \\
\text { Trombose arterial associada }\end{array}$ & ACO perene \\
\hline $\begin{array}{l}\text { TEV e } \\
\text { trombose arterial recorrentes }\end{array}$ & ACO perene + AAS \\
\hline $\begin{array}{l}\text { ACO, anticoagulação oral (cumar } \\
\text { TH, trombofilia hereditária (deficiê }\end{array}$ & $\begin{array}{l}\text { ácido acetil salicílico. } \\
\text { mbina, proteína C, proteína S, fator V Leiden, mutação G20210A da protrombina) }\end{array}$ \\
\hline
\end{tabular}

A presença de trombocitopenia, principalmente se contagem de plaquetas for inferior a $80 \times 10^{9} / \mathrm{L}$, aumenta o risco de hemorragia durante o tratamento com anticoagulante oral. Caso haja sangramento devido à trombocitopenia imune, sem evidência prévia de trombose, o paciente deverá receber tratamento semelhante ao realizado para Púrpura Trombocitopênica Imune, inclusive com esplenectomia, se a mesma for indicada.

Em casos de SAF em mulheres com abortos de repetição, para evitar novos abortos, a melhor terapêutica (demonstrada em dois estudos controlados, prospectivos e randomizados) é a utilização de heparina não fracionada (HNF), associada à aspirina ${ }^{(8,9,15)}$. Em um estudo, foi usada dose de HNF para manter a razão entre TTPA do paciente e do controle em torno de 1,5. A amostra de sangue era colhida entre as duas doses diárias da HNF. Em outro estudo, foi utilizada HNF 5000 UI duas vezes ao dia, sem monitorização. Os resultados dos dois estudos foram semelhantes. O tratamento deve ser iniciado logo após a confirmação da gravidez. A heparina e a aspirina devem atuar sobre outros mecanismos, responsáveis por provocarem o aborto, além de evitarem trombose em vasos placentários. A aspirina, por exemplo, aumenta o nível de interleucina-3 (IL-3), promotora da invasão e expansão do trofoblasto ${ }^{(18)}$. Deve ser também ressaltado que não se recomenda a administração de corticóides a mulheres com SAF e abortos recorrentes, em decorrência da alta morbidade materna, associada à utilização desse regime durante a gestação e à sua duvidosa eficácia na SAF.

Finalmente, deve ser mencionado que muito há que se definir acerca das recomendações ótimas para profilaxia e tratamento na SAF. Trata-se, portanto, de campo controverso e as recomendações aqui apre- sentadas podem ser modificadas de acordo com a aquisição de novos dados no futuro.

\section{HEMOGLOBINÚRIA PAROXÍSTICA NO- TURNA}

A Hemoglobinúria Paroxística Noturna (HPN) foi descrita pela primeira vez em $1882^{(19 / 25)}$. Caracteriza-se por ser uma doença clonal, adquirida e rara. A incidência estimada é de 2 a 6 casos por milhão de pessoas por ano, acometendo qualquer idade, mas com idade mediana de 35 anos.

Clinicamente, apresenta-se como um quadro de hemólise intravascular, acompanhada de hemoglobinúria, pancitopenia e eventos trombóticos. A Tabela VIII ilustra a heterogeneidade da apresentação clínica da HPN (terminologia proposta em 1998) ${ }^{(19 / 25)}$.

A sobrevida estimada sem tratamento é de aproximadamente 8 anos. As principais causas de morte são complicações trombóticas e pancitopenia progressiva. Raramente, ocorre remissão espontânea (10\% dos casos) ou transformação para leucemia mielóide aguda (5\% dos casos) ${ }^{(19 / 25)}$.

Uma mutação adquirida no gene PIG-A (Fosfatidil Inositol Glican complemento grupo A) localizado no braço curto do cromossomo X (Xp22.1), é responsável pela HPN ${ }^{(19 / 25)}$. Até o momento, foram descritas 174 mutações somáticas no gene PIG-A, em casos de HPN. O gene PIG-A codifica uma proteína, PIG-A, que faz parte de uma enzima $(\alpha 1,6-\mathrm{N}$-acetil glicosaminil transferase) responsável pelo primeiro passo da formação da proteína Glicosil Fosfatidil Inositol (GPI). Essa proteína, localizada na membrana celular, funciona como suporte ("âncora") para outras proteínas protetoras da membrana contra o ataque do complemento ativado (complexo C5b-9). São 


\begin{tabular}{|llll|}
\hline \multicolumn{2}{|l|}{ Tabela VIII: Heterogeneidade clínica da HPN. } & \\
\hline Quadro Clínico & Achado Laboratorial & Tamanho do clone HPN & Nomenclatura \\
\hline Hemólise \pm trombose & $\begin{array}{l}\text { Anemia } \\
\text { Outra citopenia: }+ \text { ou ausente }\end{array}$ & Grande & HPN plenamente manifesta \\
\hline Hemólise \pm Trombose & $\begin{array}{l}\text { Anemia } \\
\text { Outra(s) citopenia(s): +/++ }\end{array}$ & Grande & HPN hipoplástica \\
\hline Púrpura e/ou Infecção & Pancitopenia ++/+++ & Grande & Anemia Aplástica (AA) / HPN \\
\hline Púrpura e/ou Infecção & Pancitopenia $++/+++$ & Pequeno & AA com clone HPN \\
\hline Trombose & Normal ou pancitopenia ++ & Pequeno & Mini-HPN \\
\hline$+:$ leve, $++:$ moderada, $+++:$ & grave & & \\
\hline
\end{tabular}

exemplos de proteínas que se ligam à GPI: o CD59 (Membrane Inhibitor of Receptor Lysis) e o CD55 (Decay Accelerating Factor). O clone de células, que apresenta deficiência completa das proteínas ligadas à GPI é denominado HPN III (ou tipo III), enquanto o que possui deficiência parcial é o HPN II (ou tipo II). Isso explica a ocorrência de hemólise na HPN, quando, por qualquer motivo, houver ativação do complemento.

Pouco se conhece sobre a patogênese da trombose na HPN. Os estudos se concentram, atualmente, em três possíveis mecanismos fisiopatológicos: a) interferência na fibrinólise, b) hipercoagulabilidade, c) hiperativação plaquetária ${ }^{(19 / 25)}$.

A redução na fibrinólise poderia ser explicada pela diminuição, na membrana celular, do receptor do ativador de plasminogênio do tipo uroquinase (u-PAR), que é uma proteína ligada à GPI. Níveis de u-PAR solúveis são mais elevados em pacientes com HPN.

$\mathrm{O}$ estado de hipercoagulabilidade pode existir pela ativação da cascata da coagulação, decorrente da liberação de micropartículas plaquetárias com atividade de conversão da protrombina em trombina e de clivagem do fator $\mathrm{X}$ ativado. A hemólise também pode resultar na liberação de substâncias das hemáceas com atividade de tromboplastina.

Finalmente, as plaquetas formadas pelo clone HPN, quando expostas ao complexo C5b-9 do complemento ativado, poderiam ser ativadas mais facilmente, o que explicaria a expressão aumentada de marcadores de ativação na superfície dessas plaquetas.

O diagnóstico de HPN é feito, atualmente, por citometria de fluxo, usando-se anticorpos monoclonais, que demonstram a diminuição de proteínas de membrana, ancoradas em GPI (principalmente CD55 e CD59) em hemáceas e granulócitos de pacientes com a doença. A sensibilidade do método é alta, permitindo a detecção de clones muitos pequenos (de aproximadamente $0,1 \%$ das células estudadas). O teste de Ham, muito utilizado no passado, é menos sensível, não conseguindo detectar clones pequenos $(<5 \%$ da população de hemáceas). $\mathrm{O}$ teste se baseia na investigação da sensibilidade das hemáceas (avaliada pelo grau de lise) ao complemento ativado por acidificação do meio.

O tratamento da HPN depende da sua apresentação clínica, variando de observação da evolução com acompanhamento clínico regular ao uso de imunossupressores ou transplante de medula óssea a depender da forma clínica da doença.

Fenômenos trombóticos agudos na HPN devem ser tratados com heparinização plena, seguida de anticoagulação oral, mantendo o RNI entre 2 e 3 . Em algumas situações, há necessidade de ser realizada terapia trombolítica. A anticoagulação oral nem sempre previne trombose no paciente com HPN e uma vez iniciada, após o primeiro episódio trombótico, deve ser feita continuamente, se não houver complicações hemorrágicas graves ou outra contra-indicação. Alguns autores indicam a anticoagulação oral, profilática, após o diagnóstico de HPN ser feito, caso não haja contra-indicação. Entretanto, na maior parte dos centros, tal estratégia não é a utilizada, isto é, anticoagulação só é iniciada após o primeiro evento trombótico.

\section{DOENÇAS MIELOPROLIFERATIVAS}

O grupo das doenças mieloproliferativas crônicas é composto por diferentes entidades clínicas, caracterizadas por uma proliferação clonal de células progenitoras da medula óssea ${ }^{(4)}$.

A Leucemia Mielóide Crônica apresenta o rearranjo $b c r-a b l$, evolui inevitavelmente para a forma blástica e raramente apresenta manifestações trombóticas. A Mielofibrose (Metaplasia Mielóide Agno- 
gênica) progride para falência da medula óssea ou transformação blástica, podendo ocorrer manifestação trombótica, principalmente em sistema porta, quando há trombocitose após esplenectomia. A Policitemia Vera (PV) e a Trombocitemia Essencial (TE) estão associadas, mais freqüentemente, à trombose venosa ou arterial, manifestações estas associadas a aumento de morbidade e mortalidade nesses pacientes.

Há uma grande variação da frequiência de eventos trombóticos entre os estudos feitos até o momento, podendo ser tão alta quanto $80 \%$ na TE e $60 \%$ na PV.

A maioria dos eventos trombóticos ocorre na apresentação ou durante os dois anos que precedem o diagnóstico da doença mieloproliferativa. Trombose arterial é comum, acometendo coronárias, sistema nervoso central e vasos periféricos. Os territórios venosos, geralmente envolvidos, são veias mesentérica, porta, cava inferior e cerebrais.

A eritromelalgia, descrita em 1878, por Mitchel, ocorre mais frequientemente na $\mathrm{TE}$ e se caracteriza por eritema e dor nas extremidades, podendo evoluir para um quadro isquêmico grave e até gangrena ${ }^{(4,5)}$. No exame anatomopatológico dessas áreas, encontram-se um expessamento da camada íntima das arteríolas e microtrombose. A resposta à aspirina é excelente, aliviando e, na maioria das vezes, revertendo o quadro clínico. Há ainda descrição de uma síndrome neurológica, transitória e de início súbito, que inclui cefaléia, escotomas, hemiparesia e disartria, talvez desencadeada por microoclusões plaquetárias, em pequenos vasos, sendo responsiva ao uso de aspirina e citorredução.

Os mecanismos envolvidos na trombofilia das doenças mieloproliferativas são complexos ${ }^{(4,5,26)}$. O hematócrito e a contagem de globúlos brancos elevados provocam um aumento da viscosidade do sangue, tornando seu fluxo mais lento na microcirculação. Adicionalmente, pode ocorrer obstrução de pequenos vasos, principalmente pulmonares e cerebrais, por leucócitos imaturos.

A associação entre trombose e número de plaquetas elevado é menos precisa. Estudo feito com pacientes apresentando TE evidenciou um maior risco de trombose, quando há persistência de valores plaquetários entre 800 e $1000 \times 10^{9} / \mathrm{L}$, embora graves complicações trombóticas tenham sido relatadas em $15 \%$ dos pacientes com contagens de plaquetas menores que $500 \times 10^{9} / \mathrm{L}$. Altas contagens de plaquetas $\left(>1.500 \times 10^{9} / \mathrm{L}\right)$ estão associadas a manifestações hemorrágicas, principalmente quando aspirina está sendo usada concomitantemente.
Talvez haja uma maior ativação plaquetária em pacientes com PV e TE, nos quais foram detectados níveis elevados de tromboxane $\mathrm{A}_{2}$. Há controvérsia se estudo de agregação plaquetária apresenta valor preditivo para trombose nesses pacientes.

Como a normalização do número de plaquetas e o uso de agentes antiagregantes não eliminam completamente o risco de trombose, devem existir outros mecanismos que fazem parte da fisiopatologia da trombose, em doença mieloproliferativa crônica.

Redução nos níveis de anticoagulantes naturais (antitrombina, proteína $\mathrm{C}$ e proteína $\mathrm{S}$ ) e resistência à proteína $\mathrm{C}$ ativada foram demonstradas em pacientes com PV e TE, que apresentaram eventos trombóticos. Entretanto, não se sabe se essas alterações são consequiência ou causa dos fenômenos trombóticos. Em adição, sabe-se que o uso de quimioterápicos é freqüentemente associado à deficiência adquirida de proteínas $\mathrm{C}$ e $\mathrm{S}$, o que dificulta a interpretação dos resultados de seus níveis plasmáticos nos pacientes com doenças mieloproliferativas.

Finalmente, outro mecanismo de trombogênese poderia envolver um defeito na fibrinólise, causado pelo elevado nível de inibidor do ativador do plasminogênio (PAI-1).

O tratamento feito para a doença mieloproliferativa crônica, na tentativa de reduzir a proliferação clonal, contribui para a prevenção de eventos trombóticos. Pacientes com PV têm sido tratados com sangrias terapêuticas e agentes alquilantes, com preferência a hidroxiuréia, para a manutenção do hematócrito entre 40 e $45 \%$. O tratamento para TE também é feito com agente citorredutor (hidroxiuréia) ou outras opções, como anagrelide, que é um agente seletivo para bloquear maturação de megacariócitos, diminuindo a liberação de plaquetas. O uso de aspirina é um assunto controverso. Alguns trabalhos mostram maior morbidade que benefício.

\section{NEOPLASIAS}

Eventos tromboembólicos ocorrem em aproximadamente 10 a $15 \%$ dos pacientes com neoplasia. Considerando-se achados de necrópsia, a freqüência atinge $30 \%$. Trata-se da segunda causa mais comum de óbito entre os pacientes com neoplasia ${ }^{(4,5)}$.

As neoplasias mais freqüentemente associadas a complicações trombóticas são as localizadas em pulmão, pâncreas (principalmente corpo e cauda), estômago, intestinos, ovário e próstata. 
A incidência de neoplasia é maior em indivíduos que apresentaram trombose venosa idiopática, principalmente se for recorrente. Assim sendo, deve ser feita uma detalhada avaliação desses pacientes, em busca de dados que apontem para a presença de neoplasia não manifesta, incluindo exame físico com toque retal, pesquisa de sangue oculto nas fezes, análise da urina, hemograma, função renal e hepática, raio $\mathrm{X}$ de tórax e ultra-som de abdome.

Os eventos trombóticos são descritos tanto em território venoso como em arterial, podendo ocorrer anos antes do surgimento da neoplasia, ou mesmo ser o seu primeiro sinal.

A Síndrome de Trosseau caracteriza-se por tromboflebite superficial migratória, envolvendo extremidades superiores e inferiores. Trata-se de quadro grave, não responsivo à warfarin, sendo necessário o uso de heparina.

Outras manifestações, envolvendo episódios tromboembólicos em pacientes com neoplasia, são as endocardites trombóticas não bacterianas e a coagulação intravascular disseminada (CIVD). A endocardite trombótica não bacteriana corresponde a vegetações estéreis, mais freqüentes em válvulas mitral e aórtica, formadas por plaquetas e fibrina. Episódios de embolização são comuns para baço, rim, extremidades, sistema nervoso central e coronárias. A CIVD tem sido diagnosticada em até $15 \%$ dos pacientes com neoplasias. Na leucemia promielocítica aguda (leucemia mielóide aguda M3), CIVD é observada em virtualmente $100 \%$ dos casos. A forma crônica de CIVD é a mais comum nos pacientes com neoplasia, que podem, portanto, ser assintomáticos e ter mínimas alterações laboratoriais.

A presença de fatores de risco, associados com a situação clínica do paciente, podem facilitar a ocorrência de fenômenos trombóticos. Como exemplos desses fatores podemos citar: implantação de cateter venoso, imobilização prolongada, quimioterapia, terapia hormonal, alteração na anatomia dos vasos pela massa tumoral e alteração qualitativa das plaquetas.

Os mecanismos responsáveis pela trombose em neoplasias ainda não foram totalmente esclarecidos. Estudos indicam que há, provavelmente, formação de substâncias procoagulantes pelas células neoplásicas. Essas substâncias funcionariam como fator tecidual ativador do fator VII ou proteases ativadoras do fator $\mathrm{X}$. Também foi demonstrada atividade procoagulante de células mononucleares de pacientes com neoplasia de pulmão. Detecção de níveis elevados de fator de necrose tumoral (TNF) foi relatada em 50\% dos indivíduos com neoplasia em atividade. O TNF age sobre as células endoteliais, facilitando a ativação da coagulação e dificultando a fibrinólise.

O tratamento da trombose venosa, em pacientes com neoplasia, deve ser iniciado imediatamente após o diagnóstico, administrando-se doses terapêuticas de heparina não fracionada ou de baixo peso molecular por, no mínimo, 5 dias, seguindo-se a transição para anticoagulação oral, preferencialmente com warfarin, mantendo-se o RNI entre 2 e 3.

Quando existir um fator de risco associado à neoplasia, passível de remoção, como catéter endovenoso ou compressão vascular pela massa tumoral, a duração da anticoagulação oral deverá ser de 6 meses. Se não houver fator de risco adicional identificável, a anticoagulação deverá ser feita por todo o período de risco de recorrência da neoplasia. Com efeito, o risco de recorrência após interrupção da anticoagulação oral em pacientes com câncer é sabidamente alto, $\mathrm{e}$, portanto, o tratamento anticoagulante deve ser mantido enquanto a doença neoplásica estiver em atividade. Assim, em alguns casos, deverá ser perene. Caso haja contra-indicação para anticoagulação oral, poderá ser utilizado o filtro de Greenfield, instalado na luz da veia cava inferior, quando episódios de trombose forem freqüentes em membros inferiores.

Pacientes com doenças neoplásicas apresentam alto risco de ocorrência de tromboembolismo venoso pós-operatório. Assim, na eventualidade de cirurgia, encontra-se indicada profilaxia vigorosa com heparina (não fracionada ou de baixo peso molecular), que deve ser mantida por 2 a 4 semanas no período pós-operatório. Pacientes com câncer, internados para receber quimioterapia ou imobilizados no leito também devem receber doses profiláticas de heparina. Finalmente, pacientes com cateter intravenoso central implantado apresentam risco aumentado de ocorrência de trombose. Anticoagulação oral em baixas doses (mantendo-se RNI entre 1,5 e 2) ou administração de doses profiláticas de heparina são efetivos para prevenir trombose de cateter.

\section{GRAVIDEZ E PUERPÉRIO}

Durante a gravidez, existe um risco seis vezes maior de ocorrência de tromboembolismo venoso, o qual constitui causa importante de morte entre gestantes. O risco de trombose é ainda maior no puerpério, ou seja, no período de seis semanas após o parto ${ }^{(4,5)}$. 
Alguns fatores de risco podem contribuir para a ocorrência da trombose na gravidez, por exemplo: idade avançada, cesárea, imobilização prolongada, obesidade, episódio de tromboembolismo prévio e trombofilia hereditária.

Os mecanismos fisiopatológicos, envolvidos na trombogênese, em mulheres grávidas, podem estar associados às alterações da hemostasia durante a gravidez. Níveis elevados de marcadores de ativação da coagulação, como complexos trombina-antitrombina, são detectados a partir do final do primeiro trimestre. Nota-se, também, a elevação dos níveis de substâncias procoagulantes no final da gestação, principalmente o fibrinogênio. A ativação do sistema fibrinolítico diminui progressivamente ao longo da gravidez. A ativação e o "turnover" das plaquetas se intensificam, ocorrendo um maior consumo, o que resulta em leve trombocitopenia em até $10 \%$ das gestantes saudáveis.

A normalização do sistema hemostático ocorre dentro de quatro semanas após o parto, sendo mais rápida no sistema fibrinolítico, que tem sua atividade normalizada dentro de horas após a separação da placenta.

Fatores mecânicos locais, como compressão vascular pelo útero gravídico, facilitam a estase venosa em membros inferiores e conseqüentemente a trombose venosa. Outro fator local que poderia explicar a incidência três vezes maior de trombose em membro inferior esquerdo, em relação ao direito, é a compressão da veia ilíaca esquerda pela crossa da artéria ilíaca direita.

Trauma das veias pélvicas, durante o parto via vaginal, e lesão tecidual, durante o parto cesárea, podem contribuir para trombose venosa no puerpério imediato.

Os episódios tromboembólicos, em gestantes, devem ser tratados com heparinização plena, que pode ser mantida durante todo o tratamento. Embora a heparina não atravesse a placenta, atenção deve ser dada aos seus possíveis efeitos adversos na gestante como plaquetopenia, osteoporose e sangramento. Com isso, pode ser feita uma transição para a anticoagulação oral, com warfarin, durante o segundo trimestre. A anticoagulação será feita até no mínimo quatro semanas após o parto, mesmo que os seis meses de tratamento tenham sido completados antes.

Em mulheres grávidas com história prévia de trombose venosa ou embolia pulmonar (e que não estavam recebendo anticoagulação ao engravidar) há duas opções após o diagnóstico de gestação: adminis- tração de heparina (não fracionada 5000 a 10000 UI duas vezes/dia, ou heparina de baixo peso molecular) subcutânea em doses profiláticas (não há necessidade de monitorização com TTPA), ou manutenção sem heparina mas com acompanhamento clínico próximo e realização periódica de ultra-sonografia de sistema venoso de membros inferiores para diagnóstico e tratamento precoces de eventual trombose. Após o parto, a profilaxia deve ser mantida por pelo menos quatro semanas, e pode ser realizada com heparina em doses profiláticas ou com anticoagulante oral.

Em mulheres que engravidaram, quando em uso de anticoagulação oral (devido a TEV recorrente, por exemplo), o anticoagulante oral deve ser interrompido e dose plena de heparina não fracionada (mantendo prolongamento de TTPA entre 1,5 e 2,5 vezes) ou dose terapêutica de heparina de baixo peso molecular deve ser instituída ao longo do primeiro trimestre e no terceiro trimestre de gestação. No segundo trimestre, há as opções de se manter a heparina no mesmo esquema, ou de se utilizar o anticoagulante oral (warfarin), mantendo-se o RNI entre 2 e 3 . Após o parto, é reiniciado o anticoagulante oral.

\section{SÍNDROME NEFRÓTICA}

Diversas doenças renais podem cursar com síndrome nefrótica, caracterizada pela presença de edema, hiperlipidemia, hipoalbuminemia e proteinúria. Trombose venosa é complicação importante dessa síndrome, e manifesta-se com maior freqüência em território de veias renais, embora outros sítios possam ser também acometidos ${ }^{(4,5)}$. Podem contribuir para a ocorrência de trombose, na síndrome nefrótica, a diminuição dos níveis plasmáticos de antitrombina, a elevação de fatores da coagulação (fatores V, VII, VIII, X e XIII), hiper-reatividade plaquetária e hiperviscosidade sanguiínea. O tratamento de episódios de TEV, em casos de síndrome nefrótica, não difere do tratamento empregado em outras situações (heparinização plena, seguida de anticoagulação oral, por período de 6 meses). Adicionalmente, profilaxia com heparina deve ser utilizada em situações de risco.

\section{HIPERVISCOSIDADE}

Hiperviscosidade sangüínea é causa adquirida de TEV e pode ocorrer em consequiência de aumento de viscosidade do plasma, do número aumentado de eritrócitos ou leucócitos circulantes, ou de deforma- 
bilidade reduzida das células do sangue ${ }^{(4,5)}$. Viscosidade plasmática aumentada ocorre em casos de hipergamaglobulinemia (em pacientes com macroglobulinemia de Waldenström e mieloma múltiplo) ou hiperfibrinogenemia. Hiperviscosidade aumentada, decorrente de eritrocitose e leucocitose, é observada em casos de doenças mieloproliferativas (vide supra) e leucemias agudas, com altas contagens de blastos. Finalmente, nas doenças falciformes, a presença de hemáceas "falcizadas" contribui para aumento da viscosidade sangüínea e oclusão vascular. Episódios de tromboembolismo venoso nas condições ligadas a hiperviscosidade devem ser tratados como em outras situações descritas no presente capítulo.

GARCIA AA \& FRANCO RF. Acquired thrombophilias. Medicina, Ribeirão Preto, 34: 258-268, july/dec. 2001.

ABSTRACT: In this review we discuss the contribution of acquired risk factors to the occurrence of venous thromboembolism.

UNITERMS: Thrombosis. Risk Factors.

\section{REFERÊNCIAS BIBLIOGRÁFICAS}

1 - HIRSH J; KEARON C \& GINSBERG J. Duration of anticoagulant therapy after first episode of venous thrombosis in patents with inherited thrombophilia. Arch Int Med 157: 2174-2177, 1997.

2 - ROSENDAAL FR. Venous thrombosis: a multicausal disease. Lancet 353: 1167-1173, 1999.

3 - ZOLLER B; GARCIA DE FRUTOS P; HILLARP A \& DAHLBACK B. Trombophilia as a multigenic disease. Haematologica 84 : 59-70, 1999.

4 - BAUER KA. Inherited and acquired hypercoagulable states. In: LOSCALZO J \& SCHAFER AI, eds. Thrombosis and haemorrhage, $2^{\text {nd }}$ ed,. Williams \& Wilkins, p.881-890, 1998.

5 - MARDER VJ \& MATEI DE. Hereditary and acquired thrombophilic syndromes. In: COLMAN RW; HIRSH J; MARDER VJ; CLOWES AW \& GEORGE JN, eds. Hemostasis and thrombosis, $4^{\text {th }}$ ed, . Lippincott, Williams \& Wilkins, p.1242-1257, 2001.

6 - GREAVES M. Antiphospholipid antibodies and thrombosis. Lancet 353: 1348-1353, 1999.

7 - PIERANGELI SS; GHARAVIAE \& NIGEL HARRIS E. Experimental thrombosis and antiphospholipid antibodies: new insights. J Autoimmun 15: 241-247, 2000.

8 - RAI R; COHEN H; DAVE M \& REGAN L. Randomised controlled trial of aspirin and aspirin plus heparin in pregnant womem with recurrent miscarriage associated with phospholipid antibodies. Br Med J 314: 253-257, 1997.

9 - RAI R. Obstetric management of antiphospholipid syndrome. J Autoimmun 15: 203-207, 2000.

10 - DERKSEN RHWM \& DE GROOT PG. Do we know which patients with the antiphospholipid syndrome should receive longterm high dose anti-coagulation? J Autoimmun 15: 255259,2000 .
11 - WILSON WA; GHARAVI AE; KOIKE T; LOCKSHIN MD; BRANCH DW; PIETTE JC; BREY R; DERKSEN R; HARRIS EN; HUGHES GRV; TRIPLETT DA \& KHAMASHTA MA. International consensus statement on preliminary classification criteria for definite antiphospholipid syndrome. Arthritis Rheum 42: 1309-1311, 1999.

12 - NIGEL HE \& PIERANGELL SS. Equivocal antiphospholipid syndrome. J Autoimmun 15: 81-85, 2000.

13 - DIUGUID DL. Oral anticoagulant therapy for venous thromboembolism. N Engl J Med 336: 433-434, 1997.

14 - KHAMASHTA MA. Primary prevention of trombosis in subjects with positive antiphospholid antibodies. J Autoimmun 15: 249-253, 2000.

15 - KUTTEH WH. Antiphospholipid antibody-associated recurrent pregnancy loss: treatment with heparin and low-dose aspirin is superior to low-dose aspirin alone. Am J Obstet Gynecol 174: 1584-1589. 1996

16 - LOCKSHIN MD. Future trends for APS. J Autoimmun 15: 261-264, 2000.

17 - KHAMASHTAMA; CUADRADO MJ; MUJIC F; TAUB NA; HUNT BJ \& HUGHES RV. A management of thrombosis in the antiphospholipid-antibody syndrome. N Engl J Med 332: 993-997, 1995.

18 - FISHMAN P; FALACH VE; SREDNI B; MERONI PL; RUDNIKI C \& SHOENFELD Y. Aspirin modulates interleukin-3 production: additional explanation for the preventive effects of aspirin in antiphospholipid antibody syndrome. J Rheumatol 22: 1086-1090, 1995.

19 - BEUTLER E. Paroxysmal nocturnal hemoglobinuria. In: BEUTLER E; LICHTMAN MA; COLLER BS; KIPPS TJ \& SELIGSOHN U, eds. Williams Hematology, $6^{\text {th }}$ ed. McGrawHill, New York, p.419-424, 2001. 
20 - LUZZATTO L. New insights into the pathophysiology of acquired cytopenias. III. Paroxysmal nocturnal hemoglobinuria. In: AMERICAN SOCIETY of HEMATOLOGY. Education Program Book. San Francisco, p.18-38, 2000.

21 - HALL SE \& ROSSE WF. The use of monoclonal antibodies and flow cytometry in the diagnosis of paroxysmal nocturnal hemoglobinuria. Blood 87: 5332-5340, 1996.

22 - HILLMEN P. Implications of recent insights into the pathophysiology of paroxysmal nocturnal haemoglobinuria. $\mathbf{B r} \mathbf{J}$ Haematol 108: 470-479, 2000.

23 - HUGELB; SOCIÉ G; TOTI F; VUT; GLUCKMANE.; FREYSSINET $\mathrm{JM} \&$ SCROBOHACI ML. Elevated levels of circulating procoagulant microparticles in patients with paroxysmal nocturnal hemoglobinuria and aplastic anemia. Blood 93: 3451-3456, 1999.
24 - ROSTI V. The molecular basis of paroxysmal nocturnal hemoglobinuria Haematologica 85: 82-87, 2000.

25 - TREMML G; KARADIMITRIS A \& LUZZATO L. Paroxysmal nocturnal hemoglobinuria: learning about $\mathrm{PNH}$ cells from patients and from mice. Haematology 1: 12-20, 1998.

26 - BUCALOSSI A; MAROTTA G; BIGAZZI C; GALIENI P \& DISPENSA E. Reduction of antithrombin III, protein C, and protein $S$ levels and activated protein $C$ resistance in policythemia vera and essential thrombocythemia patients with thrombosis. Am J Hematol 52: 14-20, 1996.

Recebido para publicação em 28/06/2001

Aprovado para publicação em 24/08/2001 